\title{
PREDICTION METHOD FOR SEISMIC DAMAGE OF REINFORCED CONCRETE BRIDGE COLUMNS
}

\author{
Kazuhiro TSUNO ${ }^{1}$ and Robert PARK $^{2}$ \\ ${ }^{1}$ Member of JSCE, Master Eng, First Design Division, First Construction Department, Kanagawa Construction \\ Bureau, Metropolitan Express Public Corp. \\ (1-2-4 Shinkoyasu, Kanagawa-ku, Yokohama, Kanagawa 221-0013, Japan) \\ ${ }^{2}$ Phd. Eng, Emeritus Professor, Dept of Civil Eng, University of Canterbury \\ (Private Bag 4800, Christchurch, New Zealand)
}

\begin{abstract}
This research aims to determine the effect of loading pattern on the damage of a reinforced concrete bridge column. Five specimens were tested with uni-directional or bi-directional cyclic loading patterns combined with a constant axial load. In this report, a simple procedure to predict the damage and failure of a reinforced concrete column, that is subjected to an arbitrary seismic loading pattern, is proposed using the fatigue based damage model combined with the energy dissipation.
\end{abstract}

Key Words: bi-directional cyclic loading, RC column members, energy dissipation, damage index

\section{INTRODUCTION}

For the development of the performance-based design method for a bridge column, how to predict the performance of the column is an important task needing to be studied. The needed studies include how to predict the capacity of a column for displacement or energy dissipation and how to estimate the damage accumulation on the column during a major earthquake. The analytical damage estimation is a useful and effective tool not only for the performance-based design method but also for the estimation of residual energy capacity and retrofitting necessary for the damaged columns after a major earthquake. The problem here is that the ductile behaviour of a reinforced concrete column has been reported as affected by the loading pattern used in the test.

Kawashima and Koyama ${ }^{1)}$, Ozaka et al. ${ }^{2)}$, Takemura and Kawashima ${ }^{3)}$ and Hoshikuma et al. ${ }^{4)}$ reported the effect of different cyclical loading pattern in one lateral direction on reinforced concrete bridge columns. They found that the greater the number of loading cycles to the same displacement, the smaller the maximum displacement of the column before its ultimate state was reached. The maximum lateral strength of the column reached, however, was not significantly affected by the loading pattern used in the tests. Concerning bi-directional loadings, Miyaji et al. ${ }^{5)}$, Sato et al. ${ }^{6}$ and Mashiko et al. ${ }^{7)}$ revealed that there was an interaction effect between the lateral strength in two directions, perpendicular to each other of a reinforced concrete column, and the lateral strength in one direction decreased when the deflection of the column in a direction perpendicular to the measured strength was significant. The information concerning the effect of different loading patterns, however, is still limited and the damage accumulation of reinforced concrete column, in different loading patterns has not clearly understood, yet.

The aims of this research effort are to analyse the effect of the loading pattern on a reinforced concrete column that is seismically detailed and to develop a procedure to estimate the damage and the failure of the column caused by a seismic loading. In the tests for this research, some different loading patterns, including bi-directional loading patterns, based on a 
loading pattern which is regarded as the standard in New Zealand and different from that commonly used in Japan are applied to the specimens seismically detailed using the Japanese specification. The test results are reported in detail by Tsuno and Park ${ }^{8)}$ and analysed focusing on the plastic hinge zone length and the energy dissipation.

In this report, the test results are summarised again to help readers' understanding then the analysis is extended. The transition of damage index is calculated by applying a fatigue based damage model to the test results. Using this damage model and the energy dissipation calculated from the test results, a procedure to estimate the damage and predict the failure of the column is proposed and the applicability of the proposed method is confirmed.

\section{SUMMARY OF TEST}

\section{(1) Test program}

\section{a) Specimen and test set-up}

Five specimens of a reinforced concrete bridge column which was seismically detailed using the Japanese specification ${ }^{9)}$ as seen in Fig-1, were tested. Table 1 and Table 2 show the material properties of the specimens. In Table 1, $f_{y}$ is the yield stress; $E_{s}$ is the Modulus of Elasticity; $f_{s u}$ is peak stress; $\varepsilon_{s u}$ is the strain at peak stress; and $\mathcal{E}_{s f}$ is the fracture strain. Each number is the average of results from three test samples. The $6 \mathrm{~mm}$ bars did not have a yield plateau and were more brittle than the $10 \mathrm{~mm}$ bars.

\section{b) Loading patterns}

Four identical test specimens, Specimen-1 to 4, were tested with four different loading patterns and Specimen-5, with accidentally made weak-concrete due to an error in its manufacturing as can be seen in Table 2, was tested with the basic loading pattern also used for Specimen-1. The axial load was constant at about $4 \%$ of the design strength of the column concrete for all the specimens. The basic loading pattern used for Specimens- 1 and 5, shown in Fig.2, is normally used at the University of Canterbury (Park ${ }^{10)}$ ) as a "standard loading pattern" which is supposed to test well the fatigue of reinforcing bars and the damage on concrete of the column. The loading pattern used for Specimen-2 was completely opposite from the basic loading pattern. Spesimens-3 and 4 were bi-directionally loaded in the orbits seen in Fig.4 and Fig.5. For those bi-directional loading patterns, the same way of increasing the maximum displacement of each loading cycle with that of the basic loading pattern was used in each $X$ (east-west) and $Y$ (south-north) direction.

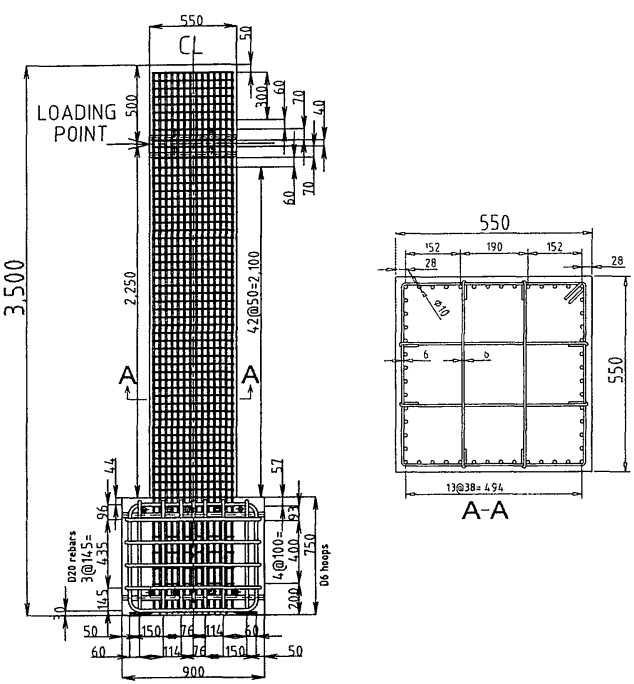

Fig.1 Reinforcement Arrangement of the Specimen [unit:mm]

Table 1 Test Results of Reinforcing Bars

\begin{tabular}{|c|c|c|}
\hline Re-bar size & $6 \mathrm{~mm}$ & $10 \mathrm{~mm}$ \\
\hline$f_{y}(\mathrm{MPa})$ & 285.6 & 306.0 \\
\hline$E_{s}(\mathrm{MPa})$ & 212100 & 203400 \\
\hline$f_{s u}(\mathrm{MPa})$ & 485.4 & 438.8 \\
\hline$\varepsilon_{s u}$ & 0.0777 & 0.1920 \\
\hline$\varepsilon_{s f}$ & 0.0992 & 0.2994 \\
\hline
\end{tabular}

Table 2 Average Concrete Compressive Strength on the Day of Test

\begin{tabular}{|c|c|c|}
\hline $\begin{array}{c}\text { Specimen } \\
\text { No. }\end{array}$ & \multicolumn{2}{|c|}{ Average Compressive Strength (MPa) } \\
\cline { 2 - 3 } & Column & Base-block \\
\hline 1 & 30.7 & 19.6 \\
\hline 2 & 30.7 & 19.6 \\
\hline 3 & 27.0 & 29.4 \\
\hline 4 & 29.4 & 29.4 \\
\hline 5 & 10.9 & $* 26.6$ \\
\hline
\end{tabular}

$* 28^{\text {th }}$ day

\section{(2) Test results}

\section{a) Hysteresis loops}

Fig.6 to Fig.10 show hysteresis loops of all the specimens obtained through the tests. The hysteresis loops of Specimens-3 and 4 are shown for each of $X$ (east-west) and $Y$ (south-north) directions separately in Fig.9 and Fig.10.

As seen in those figures, the absolute value of the maximum and minimum horizontal load at each loading cycle in $Y$ (south-north) direction is 10 to $20 \%$ smaller than in the $X$ (east-west) direction at the same loading stage. It shows that the lateral strength of the column was obviously affected by a horizontal loading applied in another direction, as reported by Mashiko et al. ${ }^{7}$. 


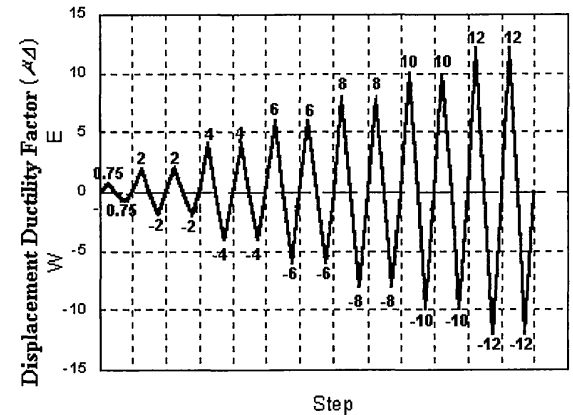

Fig.2 Basic Loading Pattern Used for Specimens-1 and 5

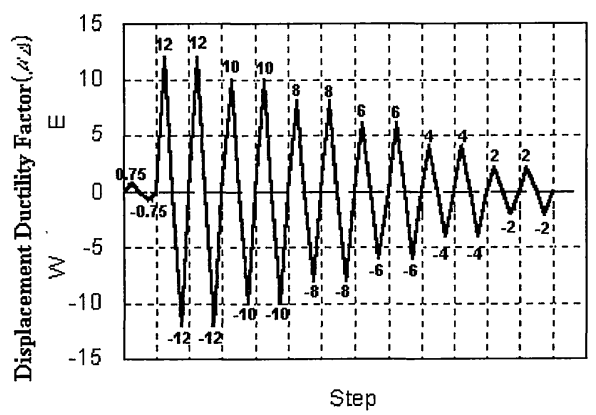

Fig.3 Loading Pattern for Specimen-2

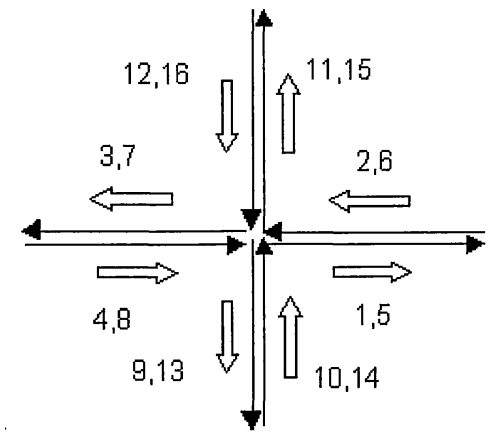

Fig.4 Loading pattern for Specimen-3: Loading orbit at the top of the specimen

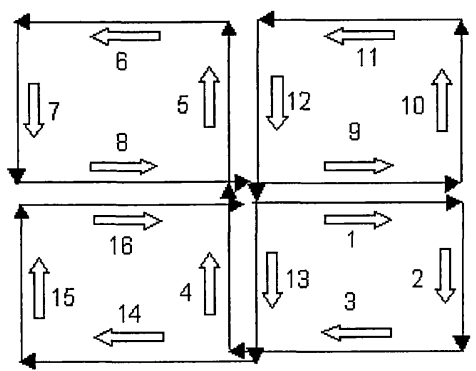

Fig.5 Loading pattern for Specimen-4:Loading orbit at the top of the specimen

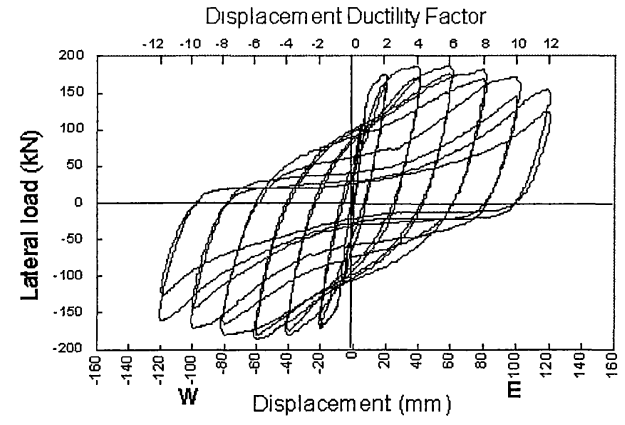

Fig.6 Measured Hysteresis Loops (Specimen-1)

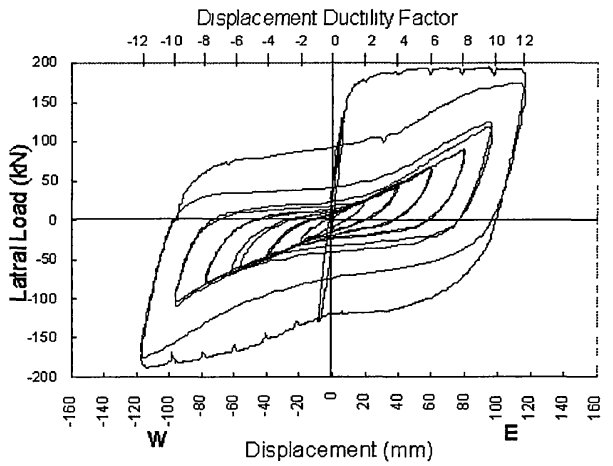

Fig.7 Measured Hysteresis Loops (Specimen-2)

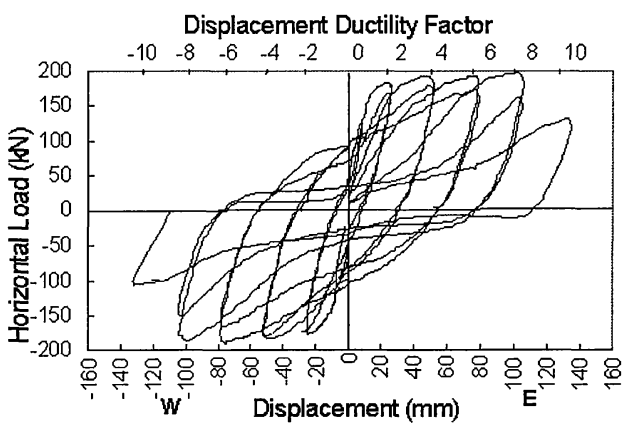

Fig.8(a) Measured Hysteresis Loops (Specimen-3): In $X$ (East-West) Direction

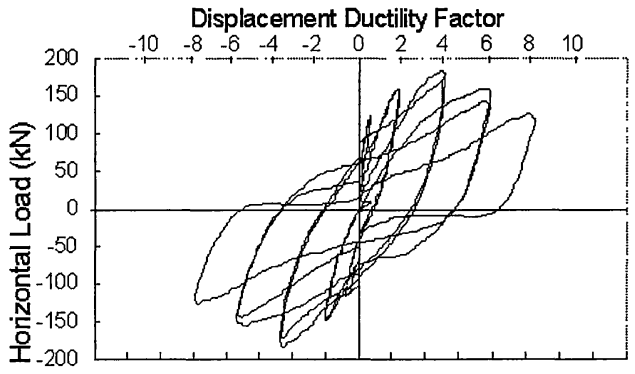

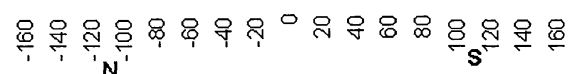
Displacement (mm)

Fig.8(b) Measured Hysteresis Loops (Specimen-3) : In $Y$ (South-north) Direction 


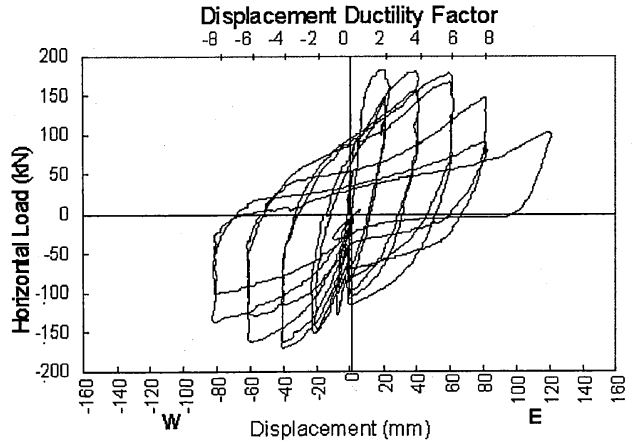

Fig.9(a) Measured Hysteresis Loops (Specimen-4) : In $X$ (East-West) Direction

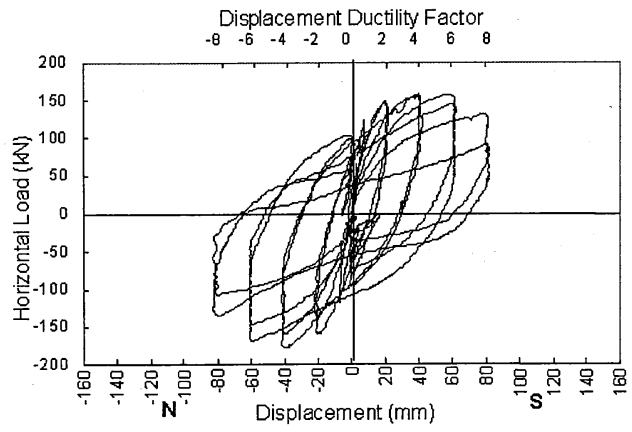

Fig.9(b) Measured Hysteresis Loops (Specimen-4): In $Y$ (South-north) Direction

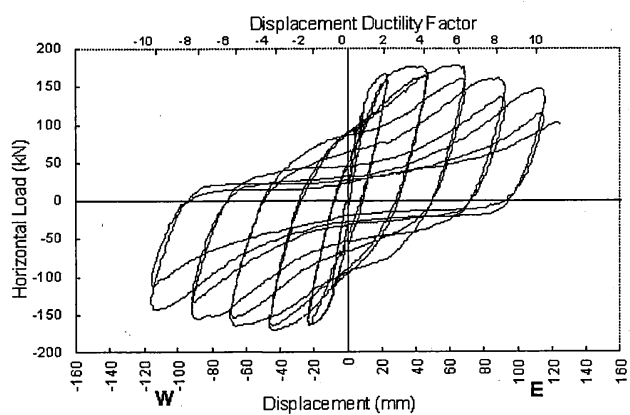

Fig.10 Measured Hysteresis Loops (Specimen-5)

\section{b) Energy dissipation}

The energy dissipated by a test specimen is defined as the area enclosed by the hysteresis loops of the lateral load-displacement relationship in both of the positive and negative side, with units of $\mathrm{kN} \cdot \mathrm{mm}$. Fig.11 to Fig.15 show the dissipated energy by each individual loading cycle and the accumulation of the dissipated energy. In Fig.13 for Specimen-3, one column in the graph is the energy dissipated by two loading cycles to a given displacement in the same direction. In Fig.14 for Specimen-4, one column is for half of a completed double-8 shaped loading cycle (one 8 shape), seen in Fig.5.

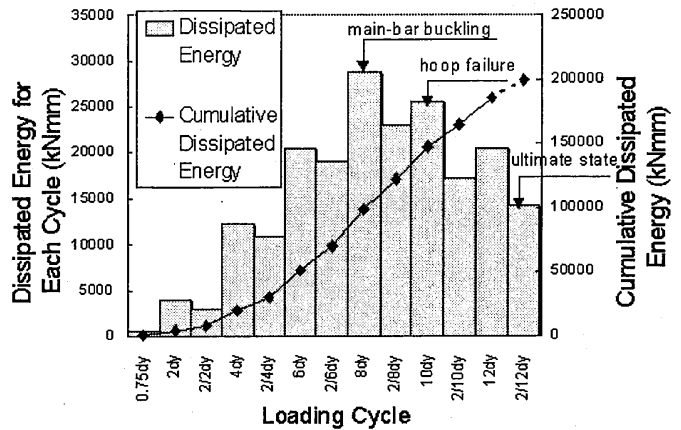

Fig.11 Individual Cycle Energy (Specimen-1)

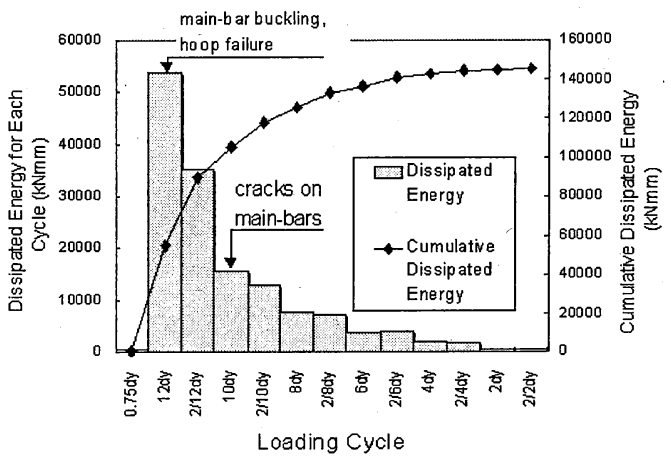

Fig.12 Individual Cycle Energy (Specimen-2)

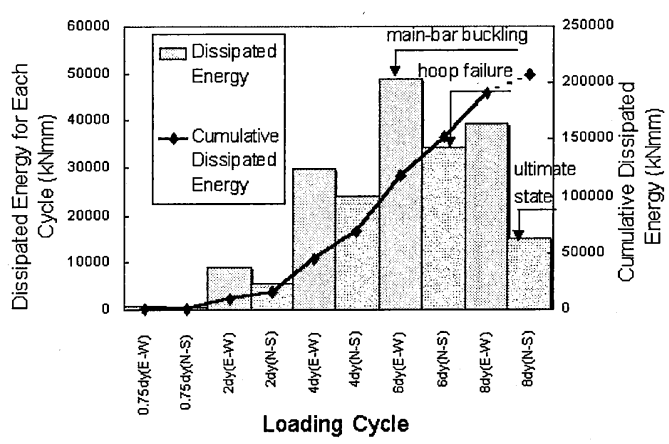

Fig.13 Individual Cycle Energy (Specimen-3)

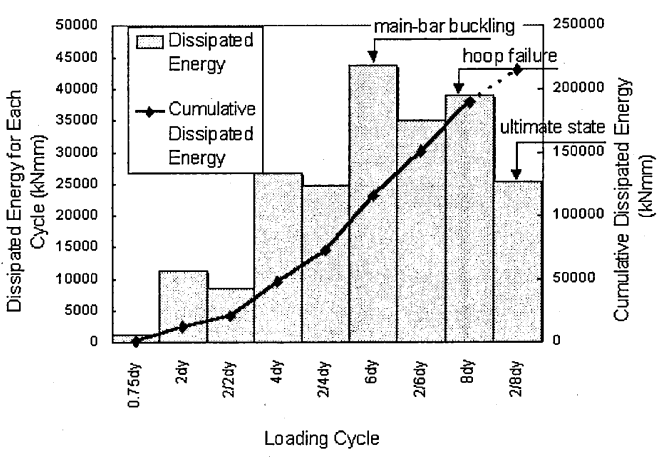

Fig.14 Individual Cycle Energy (Specimen-4) 


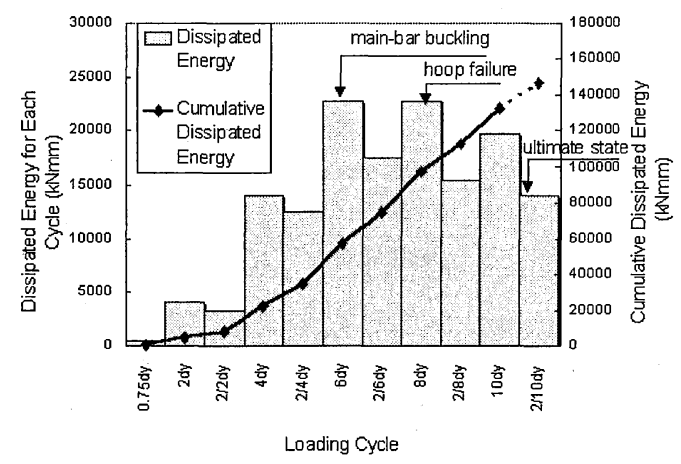

Fig.15 Individual Cycle Energy (Specimen-5)

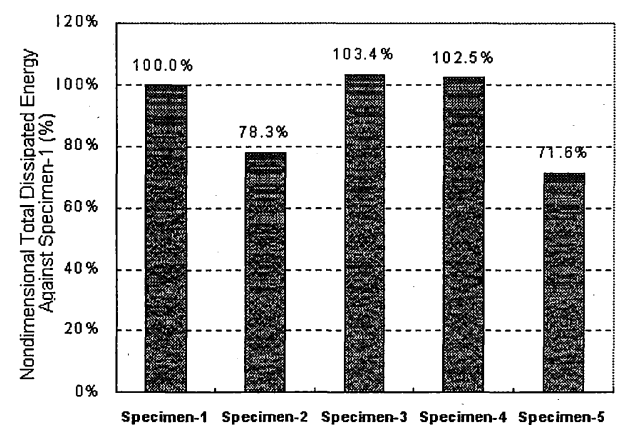

Fig.16 Total Dissipated Energy

Fig.16 shows the comparison of the total dissipated energy for all the test specimens before the specimen reached the ultimate state. The total dissipated energy of Specimens-1, 3 and 4 are approximately the same, even though bi-axial loadings were used for Specimens-3 and 4. This finding agrees with the conclusion stated by Ohno and Nishioka ${ }^{11)}$ that the total dissipated energy by a column is independent of the loading sequence. Specimen-2 dissipated much less energy than Specimens-1, 3 and 4 . The dissipated energy by Specimen-5 with a weak-concrete column is the lowest among all the five test specimens.

\section{APPLICATION OF DAMAGE INDEX}

\section{(1) Damage estimation of concrete columns}

Kunnath et al. ${ }^{12)}$ tested twelve identical specimens of circular reinforced concrete bridge column with twelve different quasi-static loading patterns and examined the tests by four damage models; a fatigue-based model described below, a softening index model, the Kratzig model (Kratzig and Meskouris ${ }^{13)}$ ) and Park-Ang model (Park and Ang ${ }^{14)}$ ). A modified cumulative fatigue model was proposed based on the experimental result as summarised below.

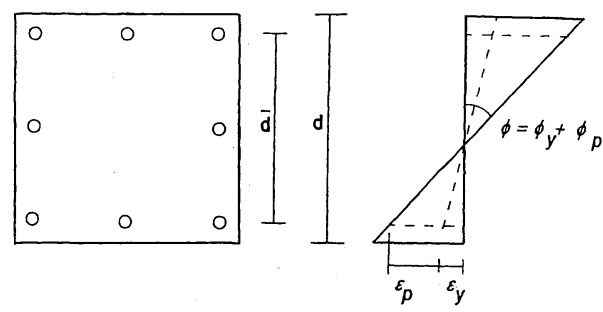

Fig.17 Curvature-Strain Relation for Plane Section

The fatigue-based damage model used by Kunnath et al. is a variation of the procedure developed by Mander and Cheng ${ }^{15)}$. The Coffin ${ }^{16)}-$ Manson ${ }^{17)}$ equation formulates the fatigue behaviour of the longitudinal bars under reversed cyclic loading as:

$$
\varepsilon_{p}=\varepsilon_{f}^{\prime}\left(2 N_{f}\right)^{c}
$$

where, $\varepsilon_{p}$ is plastic strain amplitude, $\varepsilon_{f}^{\prime}$ is a material constant to be determined from fatigue testing and $N_{f}$ is the number of complete loading cycles to the appearance of the first fatigue crack on the bar. Mander et al. ${ }^{18)}$ experimentally obtained the following expression for $\mathrm{Eq}(1)$.

$$
\varepsilon_{p}=0.08\left(2 N_{f}\right)^{-0.5}
$$

Kunnath et al. ${ }^{12)}$ used the strain-curvature relationship descrebed as $\mathrm{Eq}(3)$ in their test analysis, assuming that the section strains vary linearly as shown in Fig.17.

$$
\varepsilon_{p}=\phi_{p} \bar{d} / 2
$$

where $\phi_{p}$ is plastic curvature, and $\bar{d}$ is distance between centres of longitudinal bars. During actual tests, the neutral axis of the section does not always stays at the centre of the section. It is supposed, however, that the total plastic strain amplitude of a main bar becomes equal to twice $\phi \bar{d} / 2$ after one completed loading cycle with the same displacement or curvature to both of the opposite lateral directions, as long as the section strains vary linearly and the main bar, of which the strain amplitude is examined, is located outside of the neutral axis.

Assuming the plastic rotation $\theta_{p}$ is at the centre of the plastic hinge of vertical length $L_{p}$ (Paulay and Priestley ${ }^{19)}$ ) and neglecting shear, plastic curvature $\phi_{p}$ is expressed by $\mathrm{Eq}(4)$.

$$
\phi_{p}=\frac{\theta_{p}}{L_{p}}=\frac{\delta_{p} /\left(h-0.5 L_{p}\right)}{L_{p}}
$$


where, $\delta_{p}$ is the plastic displacement and $h$ is member length. From $\mathrm{Eq}(2), \mathrm{Eq}(3)$ and $\mathrm{Eq}(4)$, the number of cycles to failure $N_{f}$ is obtained by Eq(5).

$$
N_{f}=2\left(\frac{0.08 L_{p}\left(h-0.5 L_{p}\right)}{\delta_{p} \bar{d}}\right)^{2}
$$

Jeong and Iwan ${ }^{20)}$ evaluated seismically induced fatigue damage on reinforced concrete columns by $\mathrm{Eq}(6)$. This formulation is an extension of the well-known Miner's rule.

$$
D=\sum_{i} \frac{n_{i} \mu_{i}}{n_{f} \mu}
$$

Where, $D$ is cumulative damage (Damage Index), $n_{i}$ is the number of cycles at a given amplitude to ductility factor $\mu_{i}$ and $n_{f}$ is the number of cycles to failure at a specified ductility factor $\mu$. Kunnath et al. re-defined $\mathrm{Eq}(6)$ combining it with $\mathrm{Eq}(5)$ as,

$$
D=\sum \frac{1}{2 N_{f}}
$$

$D$ takes a value from 0 to 1.0 . The member is assumed to have no damage at $D=0$, and $D=1.0$ corresponds to the failure of the member.

Kunnath et al. modified $\mathrm{Eq}(2)$ to $\mathrm{Eq}(8)$, using their experimental results for circular flexurally reinforced concrete columns that are seismically detailed using AASHTO (or CALTRANS).

$$
\varepsilon_{p}=0.065\left(N_{f}\right)^{-0.436}
$$

Using $\mathrm{Eq}(8), \mathrm{Eq}(5)$ becomes

$$
N_{f}=\left(\frac{0.065 L_{p}\left(h-0.5 L_{p}\right)}{\delta_{p} \bar{d}}\right)^{1 / 0.436}
$$

The material properties of the columns used by Kunnath et al. are shown in Table 3.

The model coefficients in $\mathrm{Eq}(8)$ were obtained based on an exprimental fitting of the Coffin-Menson fatigue expression using the results from constant-amplitude testing of some specimens. $\mathrm{Eq}(8)$ still underestimated, however, the damage of some of their specimens to some extent at the point where the load-carrying capacity of the column dropped significantly. Kunnath et al. assumed that this underestimation was a result of the earlier confinement failure occurred prior to low-fatigue failure of the longitudinal reinforcing bars when low ampletude loading cycles were predominant in the test.
Table 3 Material Properties of Columns tested by Kunnath et al.

\begin{tabular}{|l|l|r|}
\hline \multicolumn{2}{|l|}{ Compressive strength of concrete } & $30.9-40.1 \mathrm{MPa}$ \\
\hline $\begin{array}{l}\text { Longitudinal } \\
\text { bar }(\phi 9.5 \mathrm{~mm})\end{array}$ & Yield stress & $422-476 \mathrm{MPa}$ \\
\cline { 2 - 3 } Spiral wire & Peak stress & $650-733 \mathrm{MPa}$ \\
\hline$(\phi 4.0 \mathrm{~mm})$ & Yield stress & $398-419 \mathrm{MPa}$ \\
\cline { 2 - 3 } & Peak stress & $455-471 \mathrm{MPa}$ \\
\hline
\end{tabular}

\section{(2) Calculation of cumulative damage}

The cumulative damage of the test specimen during the test, $D$, is analysed using the fatigue model explained in §3.(1) and the constants suggested by both Mander et al. and Kunnath et al. shown in Eq(2) and $\mathrm{Eq}(8)$, respectively. Fig.18 to Fig.24 show the transition of the damage index $D$ during the tests.

All the graphs are plotted until the "ultimate state" except Specimen-2 which was loaded in the opposite way of the basic loading pattern. The definition of the ultimate state used here is that defined by Zahn et al. ${ }^{21)}$ as the test specimen is considered to fail when the lateral strength of the column is smaller than $80 \%$ of the maximum lateral load measured during the first cycle to $\pm 2 \delta_{y}$. The inclination of the graph becomes much steeper as the test proceeds, except for Specimen-2 when $D$ reaches 1.0 (failure) earlier, at the third loading cycle $\left(\mu_{\Delta}=10\right)$ for Mander's model and at the fifth loading cycle $\left(\mu_{\Delta}=8\right)$ for Kunnath's model.

The first two loading cycles to $\pm 0.75 \delta_{y}$ are not counted in the number of loading cycles because the fatigue model assumes that the strain of a reinforcing bar in its elastic range does not cause any damage to the bar according to the fatigue models used here. This means that the loading cycles with large displacements (large strain amplitude for main-bars) govern the damage index $D$ if the number of the loading cycle is the same for each displacement.

In the calculation of $D$ for Specimens-1, 2 and 5, the member length $h=2250 \mathrm{~mm}$, the plastic hinge zone length $L_{p}=247 \mathrm{~mm}$ calculated using $\mathrm{Eq}(10)$ suggested by Paulay and Priestley ${ }^{19)}$ and the centre-to-centre distance of the main-bars, $\bar{d}=494 \mathrm{~mm}$, were used.

$$
L_{p}=0.08 h+0.022 d_{b} f_{y}
$$

where, $h$ is the column height; $d_{b}$ is the diameter of the vertical main-bars; and $f_{y}$ is the yield strength of the vertical main-bars.

For Specimens-3 and 4, the cumulative damage of a main-bar during the tests depends on the location of the main-bar. Therefore, both a bar at a corner of the section and a bar at the centre of a face of the column were examined for a comparison. 


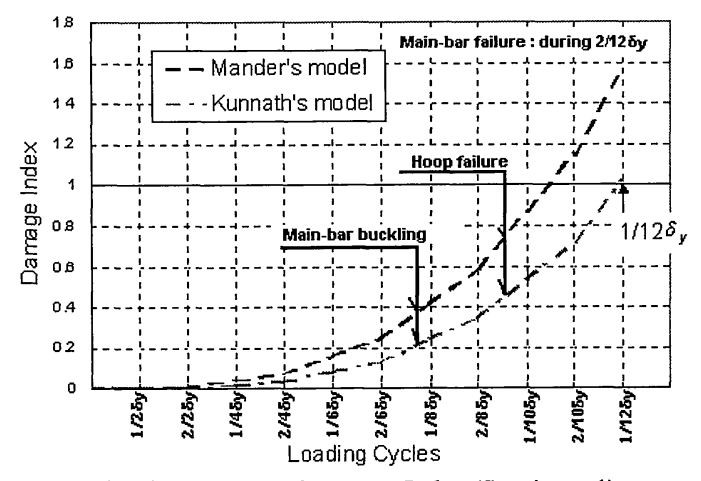

Fig.18 Transition of Damage Index (Specimen-1)

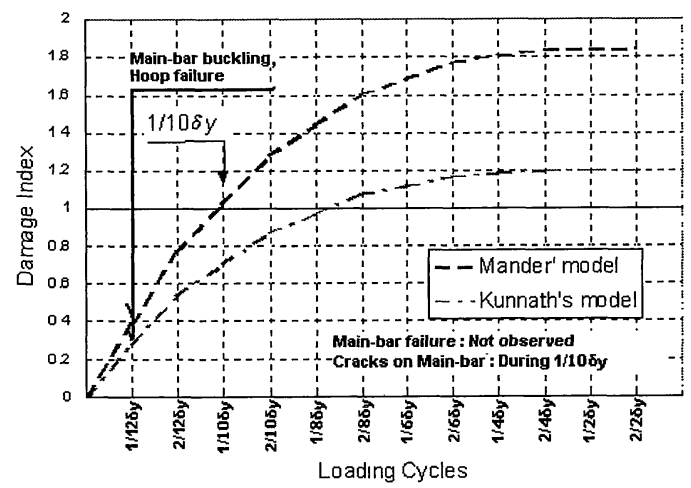

Fig.19 Transition of Damage Index (Specimen-2)

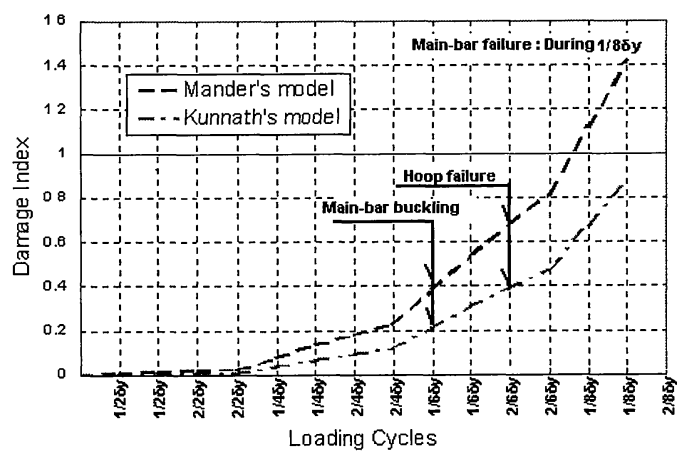

Fig.20 Transition of Damage Index (Specimen-3, corner-bar)

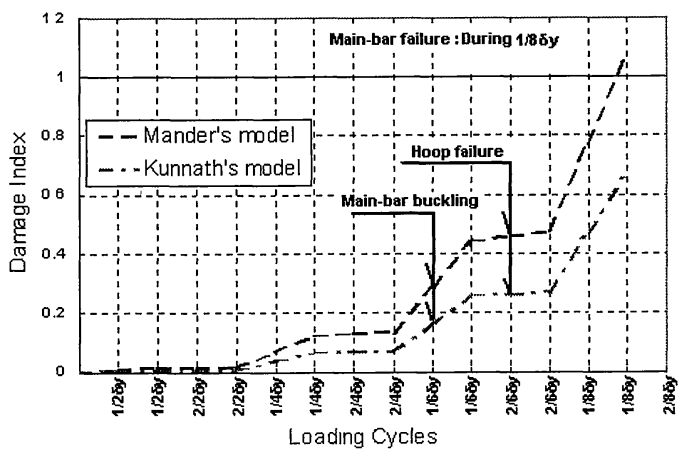

Fig.21 Transition of Damage Index (Specimen-3, centre-bar)

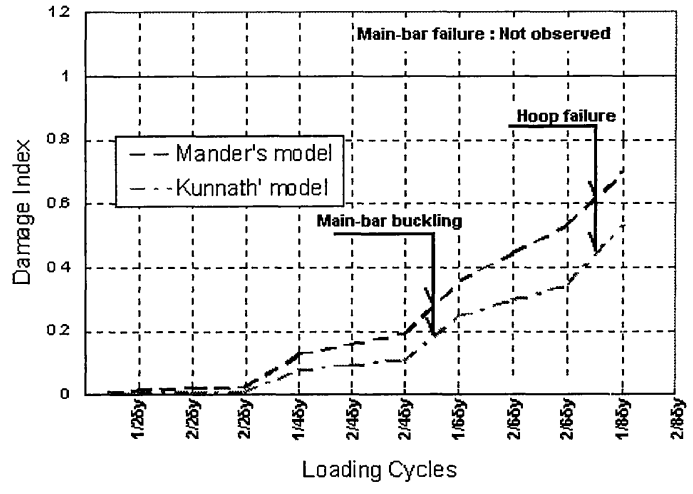

Fig.22 Transition of Damage Index (Specimen-4, corner-bar)

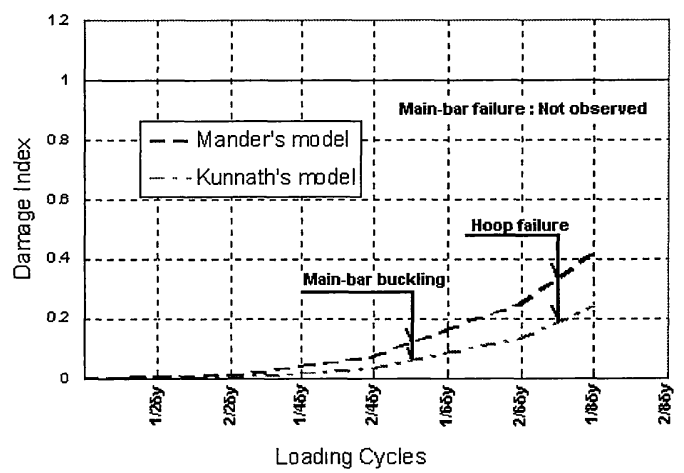

Fig.23 Transition of Damage Index (Specimen-4, centre-bar)

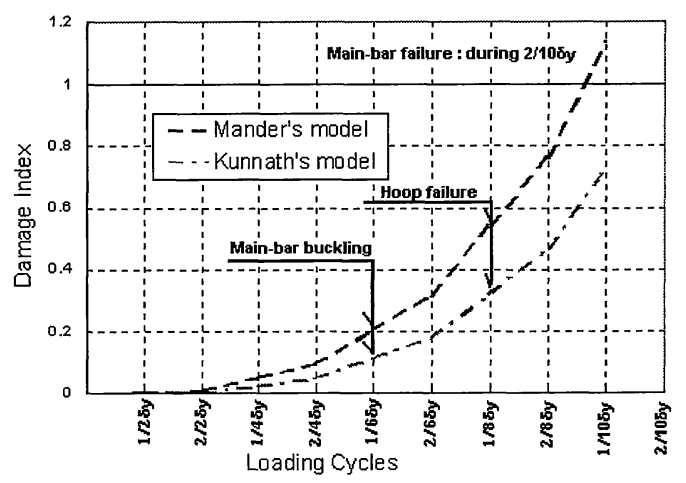

Fig.24 Transition of Damage Index (Specimen-5)

For Specimen-3, the number of the strain cycles with the same amplitude is four for a corner-bar as shown in Fig.25. Fig.25(a) shows an example of actual strain history for one loading cycle obtained in the test. Fig.25(b) shows an idealised strain history of the example shown in Fig.25(a) based on the assumption made for $\mathrm{Eq}(3)$. A centre-bar, however, has two strain cycles with the same amplitude as that for the corner-bar, and four additional cycles with lower strain amplitudes (see Fig.26). These additional four strain cycles are applied to the centre-bar because of the distance between the bar and the neutral axis of the column section, during the two 
loading cycles in the direction parallel to the face of the column with the centre-bar. As explained in $\S 3(1)$, the total strain amplitude of a centre bar can be obtained using $\mathrm{Eq}(3)$ when the loading direction is perpendicular to the column face where the bar is located because the bar is always at outside of the neutral axis. On the other hand, the eccentricity of the neutral axis must be considered in the calculation of the strain amplitude when the loading direction is parallel to the column face with the main-bar because the centre bar is located at inside of the neutral axis. The strain of the centre bar is always in tension in that case. $\bar{d}=200 \mathrm{~mm}$ was assumed for the calculation of the additional low strain amplitude cycles, because the distance between the centre-bar to the neutral axis of the base section was about $200 \mathrm{~mm}$ according to the moment-curvature analysis carried out using a fibre model (Mander et al. ${ }^{23)}$ ). Assuming the additional strain is only in tension as explained above, the plastic strain, which is half of the strain amplitude, can be obtained by $\operatorname{Eq}(3)$ with $\bar{d}=$ $200 \mathrm{~mm}$.

The strain histories of the corner-bar and the centre-bar of Specimen-4 in one complete loading cycle (see Fig.5) are shown in Fig.27 and Fig.28, respectively. The plateaus seen in Fig.27 and Fig.28 were formed because of the relationship between the loading pattern and the scanning speed. These plateaus are neglected in the idealised strain histories because only the plastic strain amplitude of main-bar is considered in the calculation of the damage index. As can be seen, the corner-bar has one strain cycle with larger amplitude and the other two strain cycles with smaller amplitude, and the centre-bar has only two strain cycles with the same amplitude in one completed loading cycle. $N_{f}$ of the first strain cycle of the corner-bar with larger amplitude was calculated using $\delta_{p}, L_{p}$ and $\bar{d}$ measured in the north-east and south-west direction. $\delta_{p}$ and $\bar{d}$ are obtained as

$$
\begin{aligned}
\delta_{p}\left(45^{\circ}\right) & =\sqrt{\delta_{p x}^{2} \times \delta_{p y}^{2}} \\
\bar{d}\left(45^{\circ}\right) & =\sqrt{2} \times 494=699 \mathrm{~mm}
\end{aligned}
$$

where, $\delta_{p x}$ and $\delta_{p y}$ are the plastic displacement for $X$ and $Y$ (east-west and south-north) direction, respectively. $L_{p}$ for 45 degrees was obtained as seen in Fig.29 from the relationship between the displacement at the lateral loading point and the curvature at the base of the column measured by potentiometers in the tests.

From Fig.29, $L_{p}$ for 45 degrees can be assumed to still follow $\mathrm{Eq}(10)$ when the displacement ductility factor is equal to or greater than 4 . Therefore, $L_{p}$ $=247 \mathrm{~mm}$ is used also for the 45 degree direction. A smaller value of $L_{p}$ could be used when $\mu=2$. Only one value of $247 \mathrm{~mm}$, however, is used in the calculation of the damage index all through tests, because the plastic strain of a main-bar has a very limited effect on its damage index when the displacement is relatively small, as explained in §3.(2). The smaller strain amplitude of the corner-bar and the strain amplitude of the centre-bar were assumed to be the same in the same loading cycle, and calculated using the same values of $L_{p}$ and $\bar{d}$ used for Specimen-1, 2 and 5 .

\section{(3) Applicability of damage model}

The findings from Fig.18 to Fig.24 are follows.

1) The Mander's model overestimates the damage for all the test specimens except Specimen-4.

2) The Kunnath's model estimates the failure of Specimens-1 significantly well.

3) For Specimen-2, both of the fatigue models predicted the failure at an early stage, although none of the main-bar failed all through the test. However, some cracks were found on a corner-bar during the first cycle to $10 \delta_{y}$, which was the $5^{\text {th }}$ loading cycle in Fig.3. Because the definition of the main-bar-fracture is the crack initiation for Mander's model, Mander's model predicted well the main-bar-fracture of Specimen-2, in this sense.

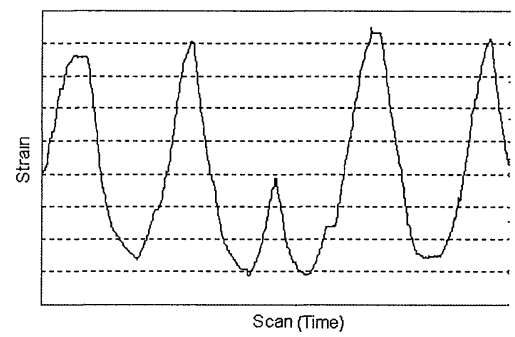

Fig.25(a) Strain History of Corner-bars in Four Loading Cycles to the Same Displacement (Specimen-3): Example of Actual History in the Test

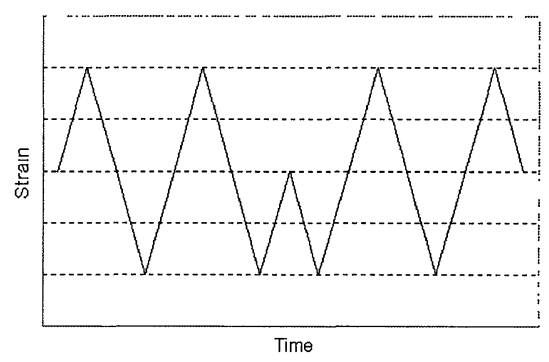

Fig.25(b) Strain History of Corner-bars in Four Loading Cycles to the Same Displacement (Specimen-3): Idealised History 


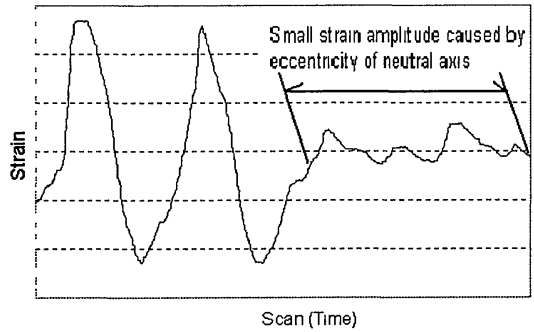

Fig.26(a) Strain History of Centre-bars in Four Loading Cycles to the Same Displacement (Specimen-3): Example of Actual History in the Test

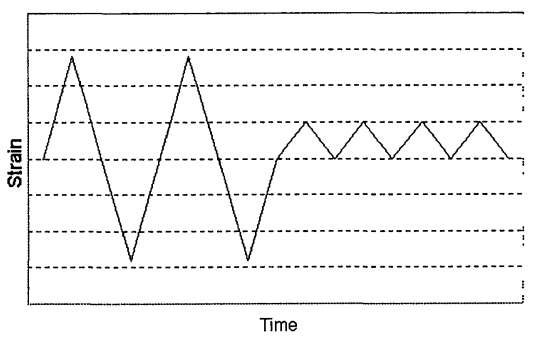

Fig.26(b) Strain History of Centre-bars in Four Loading Cycles to the Same Displacement (Specimen-3): Idealised History

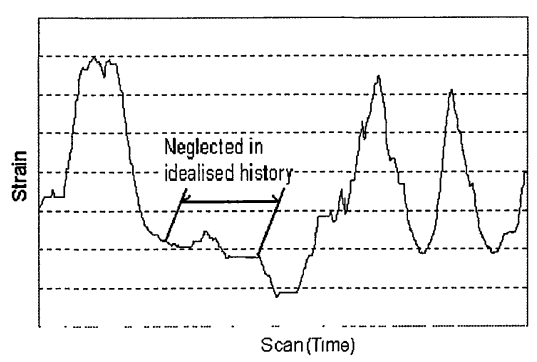

Fig.27(a) Strain History of Corner-bars in One Completed Loading Cycle (Specimen-4): Example of Actual History in the Test

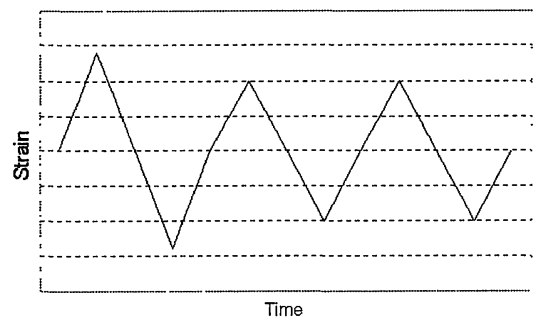

Fig.27(b) Strain History of Corner-bars in One Completed Loading Cycle (Specimen-4): Idealised History

4) The damage of the corner-bar is more severe than that of the centre-bar for Specimen-3 according to both of the damage indices by the Mander's model and the Kunnath's model. The damage index of the corner-bar calculated using the Kunnath's model corresponds well to the actual failure of Specimen-3.

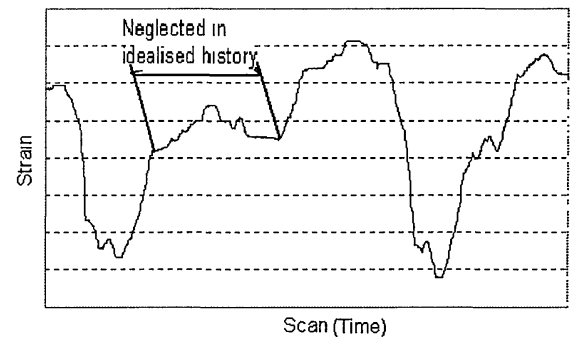

Fig.28(a) Strain History of Centre-bars in One Completed Loading Cycle (Specimen-4): Example of Actual History in the Test

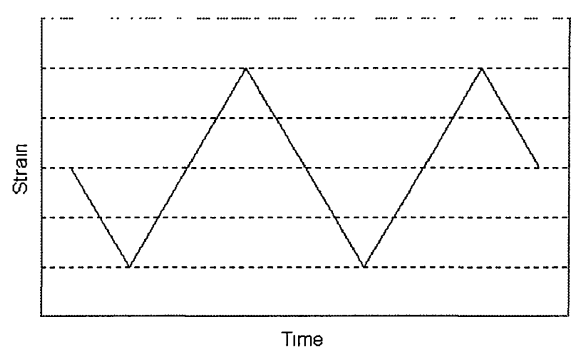

Fig.28(b) Strain History of Centre-bars in One Completed Loading Cycle (Specimen-4): Idealised History

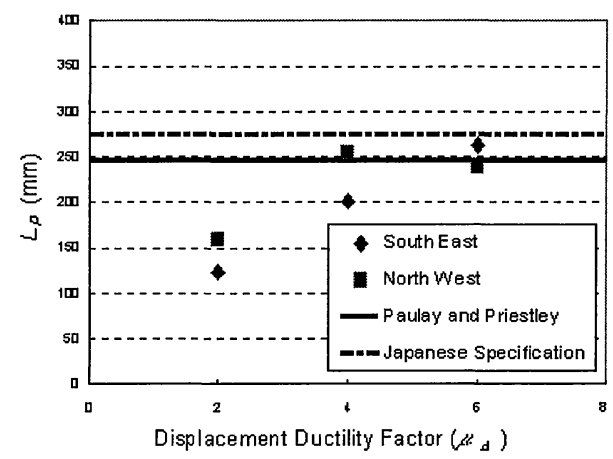

Fig.29 Plastic Hinge Zone Length for 45 Degree Axis (Specimen-4)

5) The damage of the corner-bar is critical also for Specimen-4, but both of the damage models underestimate the damage of both the corner-bar and the centre-bar.

6) The Mander's model overestimated the failure of Specimen-5 and the Kunnath's model underestimated it. No significant advantage can be seen for either the Mander's model or the Kunnath's model.

Kunnath's model predicts well the failure of a flexurally reinforced concrete column with a low axial load and seismically detailed using the Japanese specification as well as that by CALTRANS or AASHTO, if the basic loading pattern $\left(\right.$ Park $\left.^{10)}\right)$ used for Specimens- 1 and 5 in one direction is used in the test. It also predicts well the failure of a column loaded independently in two 
directions perpendicular to each other, calculating the damage index for the corner-bars. In some cases, however, it does not predict the failure of the column well. The mispredictions for the failure by the Kunnath's model could be explained by reason of the difference in the constants of $\mathrm{Eq}(2)$ and $\mathrm{Eq}(8)$. Mander's model was formulated as $\mathrm{Eq}(2)$ from experiments on steel bars to which some cyclical axial loading were directly applied. On the other hand, $\mathrm{Eq}(8)$ of Kunnath et al. ${ }^{12)}$ was derived from experiments using some reinforced concrete columns. Therefore, Kunnath's equation accounts for some effects as a composite member under a given condition, for instance the accumulated damage due to shear, axial stress and loss of confinement. It implies that the underestimation of the damage on Specimens- 4 and 5 by Kunnath's model is due to the earlier confinement failure compared to the damage on the critical main-bars of the test specimens. The first spalling of cover concrete was observed during the loading cycle with the maximum displacement of $6 \delta_{y}$ in both Specimens-3 and 4 due to the main-bar-buckling, and the confinement failure followed. The accumulated damage on the corner-bars, however, were different for Specimens-3 and 4 at the same stage due to different loading patterns. This means that the difference of the loading patterns caused the underestimation of the failure for Specimen-4. And it can be assumed that the weak cover concrete of Specimen-5 led to the earlier main-bar-buckling and confinement failure compared to Specimen-1, which was loaded in the same way with Specimen-5.

The findings and assumptions above suggest that the loading pattern and the concrete strength could affect the prediction of the failure of a reinforced concrete column by the damage models based on the fatigue of the vertical main-bars.

\section{(4) Analytical approach for failure prediction}

The analysis concerning the energy dissipation and the damage index imply that the failure of a column results from either the main-bar failure or confinement failure, and the balance of them is affected by the loading pattern applied to the specimen and the concrete strength. The fatigue based damage model suggested by Kunnath et al. ${ }^{12)}$ predicted well the ultimate state of Specimens- 1 and 3 and the Mander's model well predicted that for Specimen-2, when the fatigue of the critical main-bars (corner-bars) is relatively greater when compared with the dissipated energy. On the other hand, the failure of a column (Specimen-4) corresponds well to the cumulative dissipated energy equal to that of the same column cyclically loaded by the basic loading pattern suggested by Park ${ }^{10}$, when the fatigue of the critical main-bars is relatively low.
From these findings, it is assumed that the failure point of the column in an arbitrary cyclic loading pattern can be decided as the earliest point where the cumulative dissipated energy reaches the total dissipated energy in the basic loading pattern or the damage index reaches 1.0.

Based on the assumption above, it is tried to predict the failure of the test specimens only by an analytical approach. Then, the results of the analysis are compared to the test results.

Firstly, hysteresis loops are assumed for the loading patterns applied to the test specimens as shown in Fig.30 to Fig.34 inclusively. The modified Takeda model (Otani ${ }^{22)}$ ) is used with $\alpha=0, \beta=0$ and $r=0$ (seen in Fig.35).

The lateral strength of Specimen-1 for the second load cycle to the same displacement is assumed to be $90 \%$ of that for the first cycle. For Specimen-2, no strength degradation is assumed for the loops enclosed in any other loops. For Specimen-3, the lateral strength for the second load cycle in the $X$ (east-west) direction is assumed to be $90 \%$ of that for the first load cycle, and $80 \%$ and $70 \%$, for the first load cycle and the second load cycle in the $Y$ (south-north) direction, respectively.

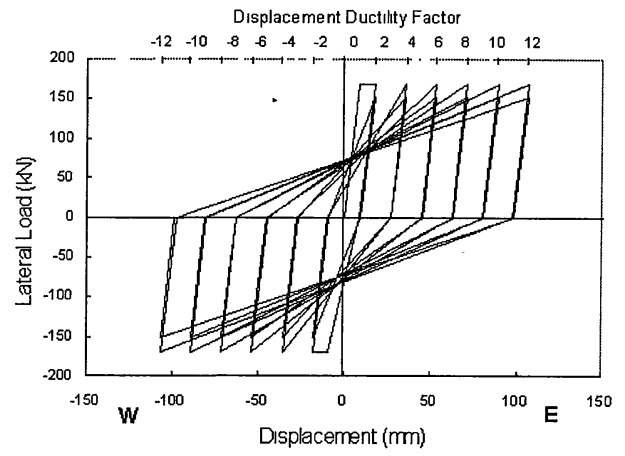

Fig.30 Assumed Hysteresis Loops for Specimen-1

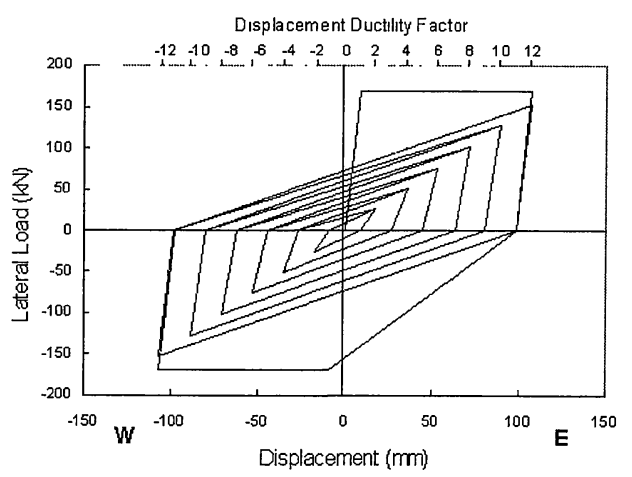

Fig.31 Assumed Hysteresis Loops for Specimen-2 


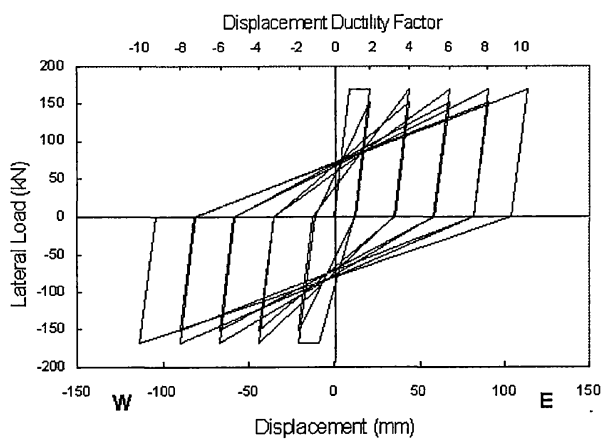

Fig.32(a) Assumed Hysteresis Loops for Specimen-3: In $X$ (East-West) Direction

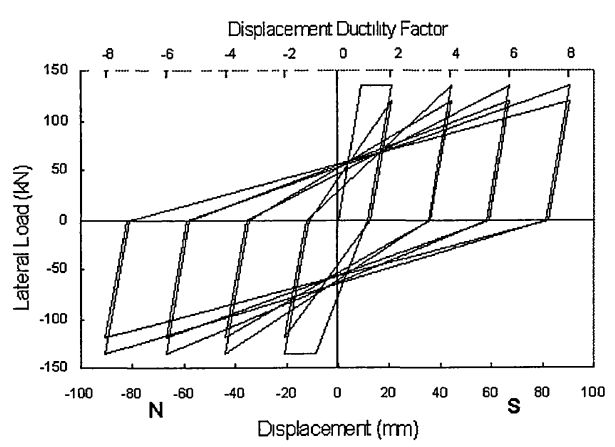

Fig.32(b) Assumed Hysteresis Loops for Specimen-3: In $Y$ (South-north) Direction

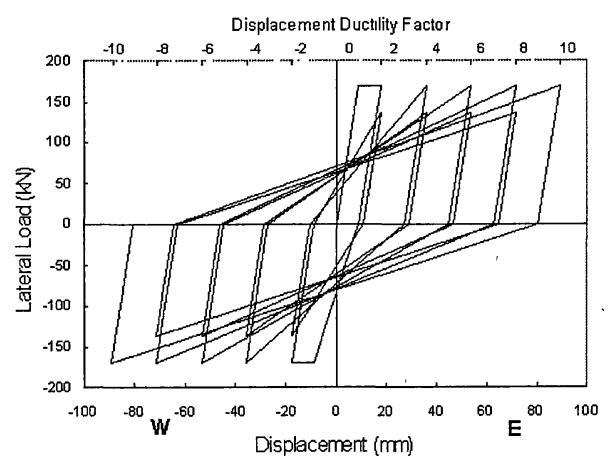

Fig.33(a) Assumed Hysteresis Loops for Specimen-4: In $X$ (east-west) Direction

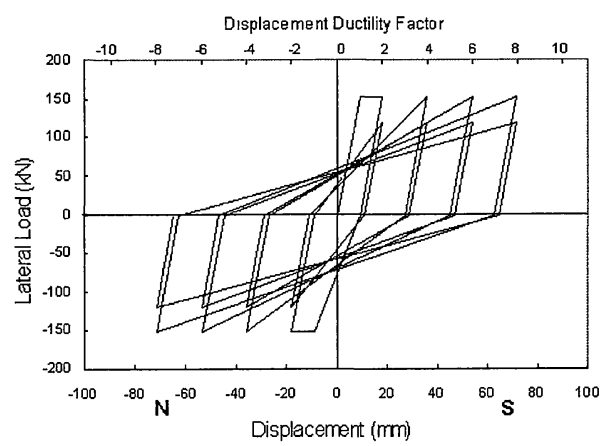

Fig.33(b) Assumed Hysteresis Loops for Specimen-4: In $Y$ (South-north) Direction

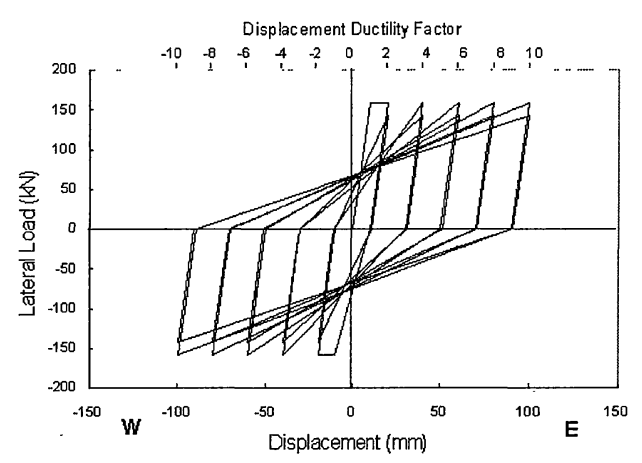

Fig.34 Assumed Hysteresis Loops for Specimen-5

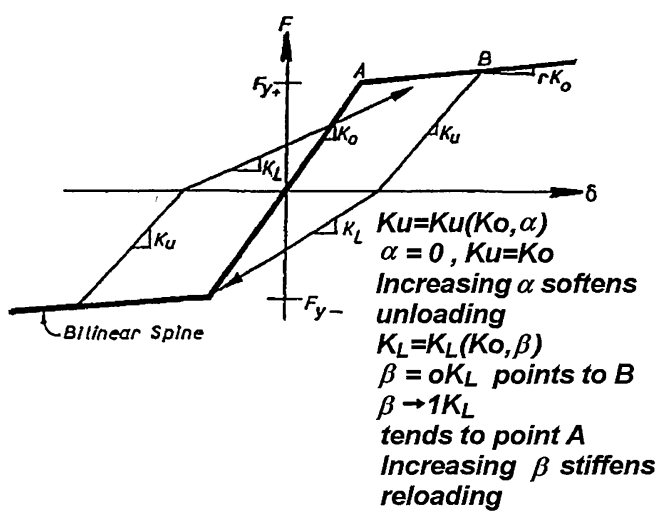

Fig.35 Modified Takeda Model (Otani ${ }^{22)}$ )

For Specimen-4, the first cycle to the same displacement is the first cycle in the $X$ (east-west) direction, the second is the first cycle in the $Y$ (south-north) direction, the third is the second cycle in the $X$ (east-west) direction and the fourth is the second cycle in the $Y$ (south-north) direction. The lateral strength of the column is decreased by $10 \%$ in each load cycles to the same displacement.

Secondly, the cumulative dissipated energy is obtained by adding up the area enclosed by the assumed hysteresis loops, and the damage index curves are calculated using the Mander's model and the Kunnath's model as shown in Fig.36 to Fig.45. For Specimens-3 and 4, the damage index is calculated only for the corner bar that is critical for the damage index as found in §3.(2).

The damage index of Specimen-1 calculated using the Kunnath's model predicts the last load cycle of Specimen- 1 as $2 / 12 \delta_{y}$ before the ultimate state, as seen in Fig.36. And the cumulative dissipated energy until $2 / 12 \delta_{y}$ is calculated as $200,800 \mathrm{kN} \cdot \mathrm{mm}$ (Fig.37), compared to $185,400 \mathrm{kN} \cdot \mathrm{mm}$ in the actual test.

From Fig.38 and Fig.39, Specimen-2 approaches closely to failure but does not fail during the test according to the Kunnath's model, but the Mander's model predicts the failure well. On the other hand, 
the total dissipated energy reaches only $160,700 \mathrm{kN} \cdot \mathrm{mm}$ which is $20 \%$ smaller than the analytical value for Specimen-1. This result is quite similar to the experimental results.

The damage index of Specimen-3, obtained using the Kunnath's model, exceeds 1.0 before the first load cycle to $10 \delta_{y}$ is completed and the cumulative dissipated energy exceeds $200,800 \mathrm{kN} \cdot \mathrm{mm}$ (which corresponds to the ultimate state of Specimen-1) before the second load cycle to $8 \delta_{y}$ is completed. Therefore, it is decided that the last load cycle before the ultimate state was taken as the first cycle to $8 \delta_{y}$, which is equal to the experimental result (Fig.40 and Fig.41).

For Specimen-4, the last load cycle before the ultimate state is chosen as the second cycle to $8 \delta_{y}$, which is also same as the experimental result (Fig.42 and Fig.43).

The analytical result of Specimen-5 is recognised as the standard case for the columns with the weak concrete, and not related to the other results (Fig.44 and Fig.45). The predicted energy dissipation capacity $145,200 \mathrm{kN} \cdot \mathrm{mm} \quad\left(2 / 10 \delta_{y}\right)$ is $9 \%$ larger than $132,800 \mathrm{kN} \cdot \mathrm{mm}\left(1 / 10 \delta_{y}\right)$ obtained in the test.

Table 4 shows the comparison of the maximum displacement ductility factor before the ultimate state between the analytical result and the actual test result. The analysed results for Specimens-1, 3, 4 and 5 correspond well to the experimental results.

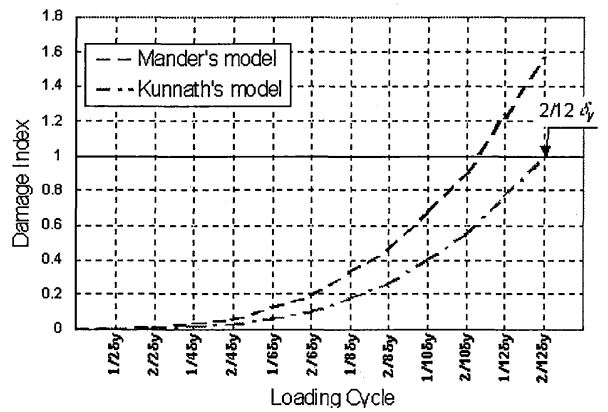

Fig.36 Damage Index of Specimen-1 (from Moment-Curvature Analysis)

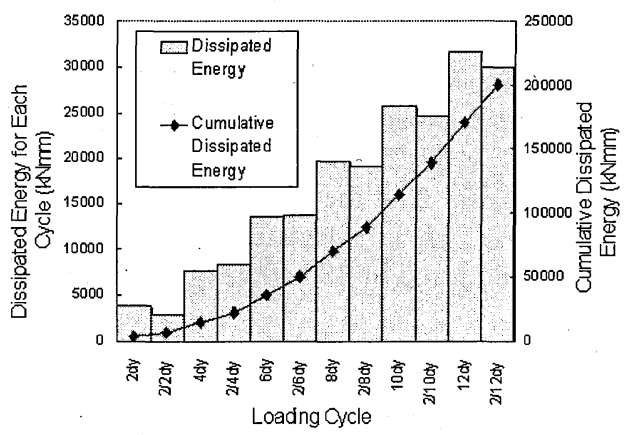

Fig.37 Energy Dissipation of Specimen-1 (from Assumed Hysteresis Loops)

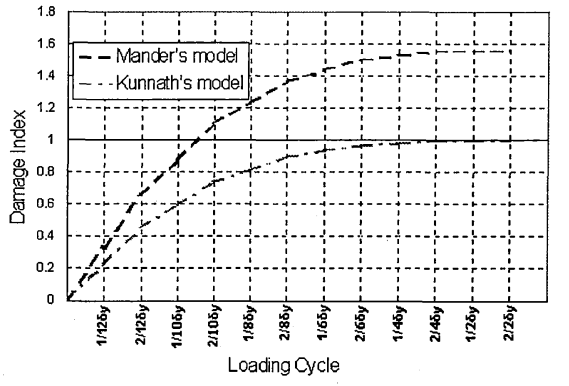

Fig.38 Damage Index of Specimen-2 (from Moment-Curvature Analysis)

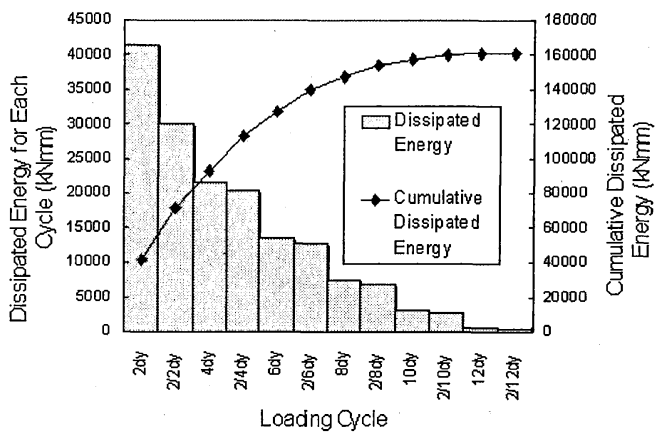

Fig.39 Energy Dissipation of Specimen-2 (from Assumed Hysteresis Loops)

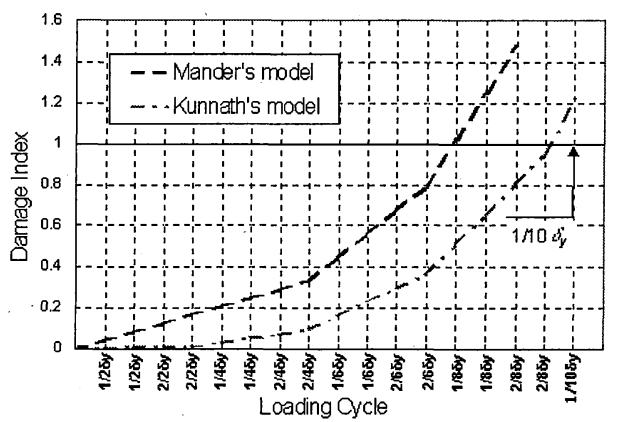

Fig.40 Damage Index of Specimen-3 (from Moment-Curvature Analysis)

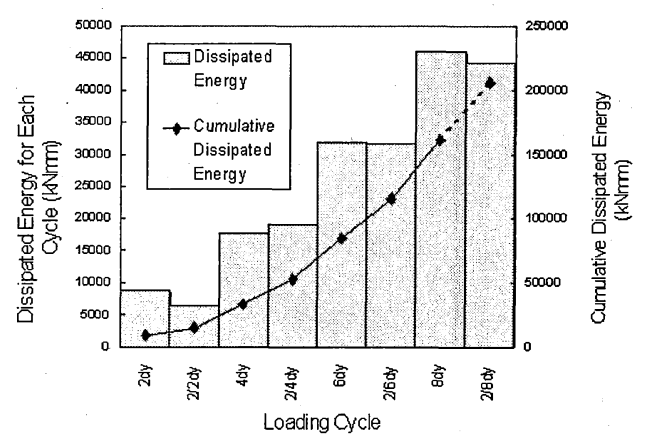

Fig.41 Energy Dissipation of Specimen-3 (from Assumed Hysteresis Loops) 


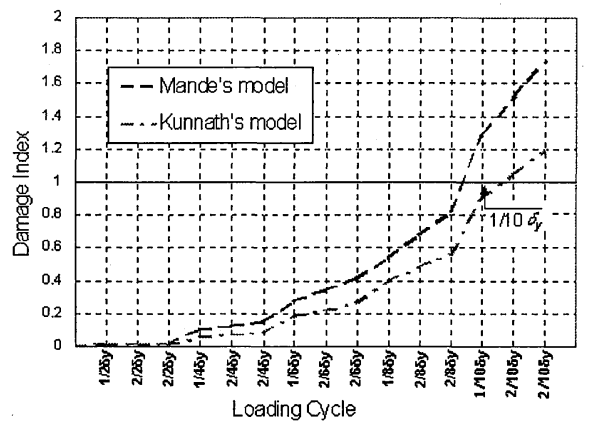

Fig.42 Damage Index of Specimen-4 (from Moment-Curvature Analysis)

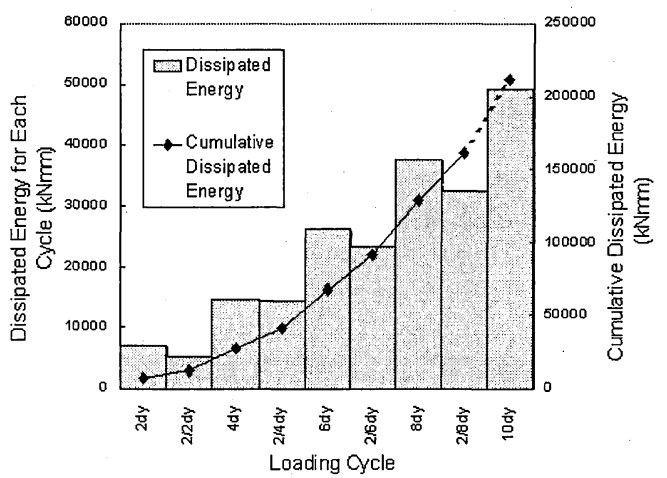

Fig.43 Energy Dissipation of Specimen-4 (from Assumed Hysteresis Loops)

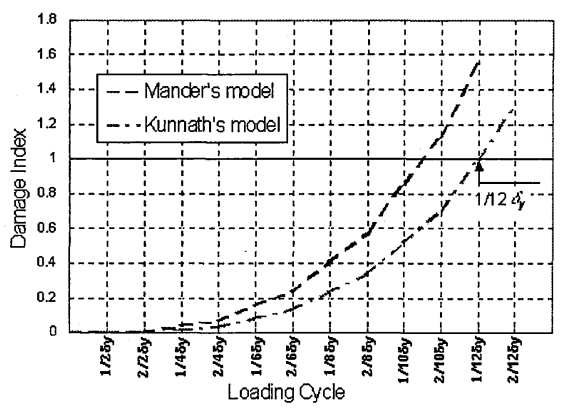

Fig.44 Damage Index of Specimen-5 (from Moment-Curvature Analysis)

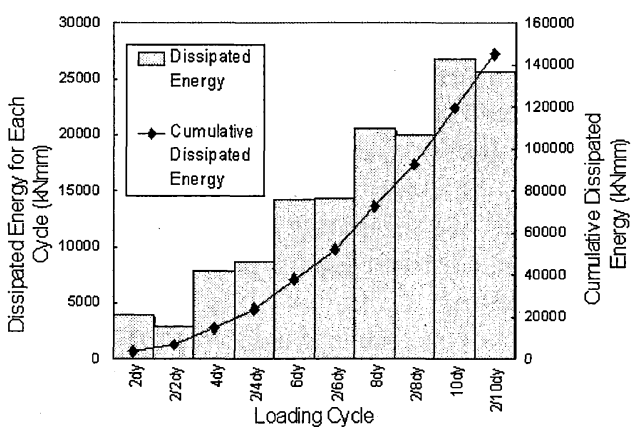

Fig.45 Energy Dissipation of Specimen-5 (from Assumed Hysteresis Loops)
Table 4 Last Load cycle before Ultimate State

\begin{tabular}{|c|c|c|c|c|}
\hline \multirow{2}{*}{ Spec- } & \multicolumn{3}{|c|}{ Last Load cycle before Ultimate State } & \multirow{2}{*}{$\begin{array}{c}\text { Exper- } \\
\text { iment }\end{array}$} \\
\cline { 2 - 5 } & $\begin{array}{c}\text { Damage } \\
\text { Index } \\
\text { (Kunnath's } \\
\text { model) }\end{array}$ & $\begin{array}{c}\text { Dis- } \\
\text { sipated } \\
\text { Energy }\end{array}$ & $\begin{array}{c}\text { Result } \\
\text { (smaller) }\end{array}$ & \\
\hline$* 1$ & $2 / 12 \delta_{y}$ & $2 / 12 \delta_{y}$ & $2 / 12 \delta_{y}$ & $1 / 12 \delta_{y}$ \\
\hline \multirow{2}{*}{2} & $\begin{array}{c}\text { Close to } \\
\text { failure } \\
\left(1 / 10 \delta_{y}:\right. \\
\text { Mander's } \\
\text { model) }\end{array}$ & $\begin{array}{c}\text { Doesn't } \\
\text { fail }\end{array}$ & & \\
\hline 3 & $2 / 8 \delta_{y}$ & $1 / 8 \delta_{y}$ & $1 / 8 \delta_{y}$ & $1 / 8 \delta_{y}$ \\
\hline 4 & $1 / 10 \delta_{y}$ & $2 / 8 \delta_{y}$ & $2 / 8 \delta_{y}$ & $2 / 8 \delta_{y}$ \\
\hline$* 5$ & $2 / 10 \delta_{y}$ & $2 / 10 \delta_{y}$ & $2 / 10 \delta_{y}$ & $1 / 10 \delta_{y}$ \\
\hline
\end{tabular}

Example: $2 / 8 \delta_{y}=$ the second cycle to $8 \delta_{y}$

* : with basic loading pattern

There is no clear ultimate state for Specimen-2, however, the failure of the Specimen-2 in the actual test can be decided as to be during the first cycle to $10 \delta_{y}$, when the initial cracks occurred on the main-bars. The dissipated energy during this load cycle was $15,600 \mathrm{kN} \cdot \mathrm{mm}$ in the test, which is only $61 \%$ of that during the first cycle to $10 \delta_{y}$ of Specimen-1, 25,600kN.mm, showing that the specimen had already been seriously damaged before that load cycle. This implies that the failure of Specimen-2, which was loaded with the extremely large first displacement, was ruled by almost only by the fatigue of the main-bars with a very small effect of confinement failure. Therefore, Mander's model might fit some extreme loading cases.

The failure of Specimen-5 is well predicted even though its concrete strength is extremely low. This result indicates that the analysis carried out here could cover a range of concrete strength, from extremely low to more normal, to predict the failure point of the column.

\section{(5) Proposal of failure prediction procedure}

Based on the results of the analysis in §3.(4), a procedure to predict the failure of a reinforced concrete column subjected to an arbitrary cyclic loading pattern is suggested as follows.

$<$ Step-1>

The lateral strength of the column and the curvature at the base of the column corresponding to the reference yield point are calculated using the moment-curvature analysis suggested by Mander et al. ${ }^{23)}$ or a fibre model introduced in the "Guide Specification of Seismic Design of Highway Bridges" "), for example. $<$ Step-2>

The elastic displacement of the column corresponding to the reference yield point is calcu- 
lated using the lateral strength and curvature obtained in $<$ Step- $1>$ and determined as $1 \delta_{y}$. The maximum displacement applied to the column for each load cycle of the basic cyclic loading pattern suggested by Park ${ }^{10)}$, is chosen.

$<$ Step-3>

The failure point, corresponding to the ultimate state defined by Zahn et al. ${ }^{21)}$ of the column in the basic cyclic loading pattern, is predicted by the damage index calculated using the Kunnath's damage model (Eqs(7) to (9)) and the plastic hinge length obtained using $\mathrm{Eq}(10)$.

$<$ Step-4>

The total dissipated energy of the column until the failure point predicted by the damage index in $<$ Step-3 $>$ is obtained by adding up the area enclosed by the hysteresis loops of the lateral load-displacement relationship based on the basic loading pattern. The hysteresis loops can be assumed using some existing hysteresis loop model (e.g. Kunnath and Reinhorn ${ }^{24)}$, Otani ${ }^{22)}$ etc.) Now, the failure point and the total dissipated energy until the failure point of the reinforced concrete column subjected to the basic loading pattern are clear.

$<$ Step-5>

For an arbitrary cyclic loading pattern, the cumulative dissipated energy is calculated by another hysteresis loop model assumed for that lording pattern, and the damage index is also calculated using the Kunnath's model and the assumed hysteresis loop. If a bi-directional loading is used, the cumulative energy is the sum of cumulative energy independently calculated in the transverse and longitudinal directions, and the damage index is calculated for a critical main-bar (corner-bar) of which the total strain amplitude in a load cycle is the largest in the column.

$<$ Step-6>

The failure point of the column in the arbitrary cyclic loading pattern is decided as the earliest point where the cumulative dissipated energy of the column reaches the total dissipated energy in the basic loading pattern (calculated in Step-4) or the damage index reaches 1.0.

\section{CONCLUSIONS}

1) The failure of a column results from either the main-bar failure or confinement failure, and the balance of them is affected by the loading pattern applied to the specimen and the concrete strength.

2) The fatigue based damage model suggested by Kunnath et al. ${ }^{12)}$ predicted well the ultimate state of a reinforced concrete column when the fatigue of the critical main-bars is relatively greater when compared with the dissipated energy.

3) The failure of a column corresponds well to the cumulative dissipated energy calculated for the same column cyclically loaded by the basic loading pattern suggested by Park ${ }^{10}$ ), when the fatigue of the critical main-bars is relatively low.

4) Based on the findings above, a procedure to predict the failure of reinforced concrete columns in arbitrary cyclic loading patterns was suggested, as described in §3.(5). The result of failure prediction carried out using the suggested procedure corresponded well to the experimental result, except only Specimen-2, which was loaded with extremely large first displacement. The failure point of Specimen-2, however, was well predicted by the damage index calculated using Mander's model. This means that other proper damage models, different from the Kunnath's model, should be chosen for some extreme loading patterns.

\section{RECOMMENDATIONS FOR FUTURE RESEARCH}

The conclusion stated in this report is applicable only for limited situation. The following recommendations for future work should provide comprehensive information for the damage estimation of reinforced concrete bridge columns.

1) Bridge columns with a much smaller aspect ratio should be tested using basically the same procedure of this research. This should provide useful information concerning the fatigue of a column with a shear failure mode, and can confirm the effect of shorter plastic hinge length with small allowable ductility factor. The axial load also should be varied.

2) A circular column, which provides more efficient confinement to the core concrete, is recommended to be tested.

3) A rectangular reinforced concrete column with the same dimension and seismically detailed by some other specifications (AASHTO, CALTRANS or New Zealand code) should be tested and compared to the result of this research.

4) Some random cyclic loading patterns bi-directionally simulating actual earthquakes are recommended to be used by quasi-static loading or shaking table.

5) The effect of an eccentric axial load on the fatigue of columns should be investigated. The rotation caused by a large eccentricity of axial load or a curved superstructure might have some effect on the fatigue of column. 
6) Columns with other types of reinforcing bars with different material properties should be tested with the same procedure of this research in order to examine the effect of the properties of reinforcing bars on the damage of the columns.

7) A simple fatigue test of a reinforcing bar with a longer effective buckling length should be carried out for the main-bars either at a corner of a hoop or adjacent to a cross-bar in a column designed using the Japanese specification.

\section{REFERENCES}

1) Kawashima, K. and Koyama, T.: Effect of Number of Loading Cycles on Dynamic Characteristics of Reinforced Concrete Bridge Pier Columns, Proceedings of JSCE, No.392/I-9, pp.205-213, April, 1988.

2) Ozaka, Y., Suzuki, M. and Kanie, H.: Effect of Loading Rate and Loading Pattern on Behaviours of Reinforced Concrete Columns (in Japanese), Structural Engineering Journal, JSCE, Vol.34A, pp.911-922, April, 1988.

3) Takemura, H. and Kawashima, K.: Effect of Hysteresis on Ductility Capacity of Reinforced Concrete Bridge Piers (in Japanese), Structural Engineering Journal, JSCE, Vol.43A, pp.849-848, March, 1997.

4) Hoshikuma, J., Unjo, S., Kawashima, K. and Nagaya, K.: A Ductility Evaluation of Reinforced Concrete Columns Based on Loading History and Plastic Curvature (in Japanese), Structural Engineering Journal, JSCE, Vol.44A, pp.877-888, March, 1998.

5) Miyaji, K., Nakazawa, N., Kawashima, K. and Watanabe, M.: Ductility Capacity of Reinforced Concrete Bridge Columns using High Strength Concrete and High Strength Reinforcement (in Japanese), Proceedings of the $6^{\text {th }}$ Symposium on Ductility Design Method for Bridges, pp.75-81, January, 2003.

6) Sato, Y., Yoshimura, M. and Tsumura, K.: Deformation Characteristics of Reinforced Concrete Column Loaded in Two Horizontal Directions, Concrete Engineering Journal, Vol.16, No.2, [2108], 1994.

7) Mashiko, N., Mutsuyoshi, H., Tanzo, W. and Machida, A.: Elasto-Plastic Behaviour of Reinforced Concrete Bridge Column Seismically Loaded in Two Horizontal Directions, Concrete Engineering Journal, Vol.16, No.2, [2212], 1994

8) Tsuno, K. and Park, R.: Experimental Study of Reinforced Concrete Bridge Piers Subjected to Bi-directional Quasi-static Loading, Proceedings of JSCE, No.752/I-66, January, 2004.

9) Japan Road Association: Guide Specification of Seismic Design of Highway Bridges (in Japanese), 1996.

10) Park, R.: Evaluation of Ductility of Structures and Structural Assemblages from laboratory Testing, Bulletin of the New Zealand National Society for Earthquake Engineering, Vol.22, No.3, September, 1989.
11) Ohno, T. and Nishioka, T.: An Experimental Study on Energy Absorption Capacity of Columns in Reinforced Concrete Structures, Structural Engineering/Earthquake Engineering, Proceedings of the Japan Society of Civil Engineers, Vol.1, No.2, October, 1984.

12) Kunnath, S.K., El-Bahy, A., Taylor, A.W. and Stone, W.C.: Cumulative Seismic Damage of Reinforced Concrete Bridge Piers, National Bureau of Standards and Technology, Technology Administration, U.S. Department of Commerce, October, 1997.

13) Kratzig, W.B. and Meskouris, M.: Nonlinear Seismic Analysis of Reinforced Concrete Frames, Earthquake Prognostics (Vogel and Brandes, editors), Verlag Friedr, Vieweg and Sohn, Braunschweig, 1987.

14) Park, Y.J. and Ang, A.H-S.: Mechanistic Seismic Damage Model for Reinforced Concrete, Journal of Structural Engineering, ASCE, 111, pp.722-739, 1985.

15) Mander, J.B. and Cheng, C.-T.: Renewable Hinge Detailing for Bridge Columns, Pacific Conference on Earthquake Engineering, Melbourne, Australia, November 20-22, 1995.

16) Coffin, L.F.Jr.: A Study of the Effects of Cyclic Thermal Stresses on a Ductile Metal, Transactions of the American Society of Mechanical Engineers, New York, Vol.76, pp.931-950, 1954.

17) Manson, S.S.: Bahaviour of Materials under Conditions of Thermal Stress, Heat Transfer Symposium, University of Michigan Engineering Research Institute, Ann Arbor, Michigan, pp.9-75, 1953.

18) Mander, J.B., Panthaki, F.D. and Kasalanati, A.: Low Cycle Fatigue Behaviour of Reinforcing Steel, Journal of Materials in Civil Engineering, ASCE, Vol.6, No.4, 1994.

19) Paulay, T. and Priestley, M.J.N.: Seismic Design of Reinforced Concrete and Masonry Buildings, John Wiley and Sons, New York, 1992.

20) Jeong, G.D., and Iwan, W.D.: The effect of earthquake duration of the damage of structures, Earthquake Engineering Structural Dynamics, Vol.16, pp.1201-1211, 1988.

21) Zahn, F.A., Park, R. and Priestley, M.J.N.: Design of Reinforced Concrete Bridge Columns for Strength and Ductility, Department of Civil Engineering, University of Canterbury, New Zealand, March, 1986.

22) Otani, S.: A Computer Program for Inelastic Response of R/C Frames to Earthquakes, Report UILU-Eng-74-2029, Civil Engineering Studies, University of Illinois at Urbana-Champaign, November, 1974.

23) Mander, J.B., Priestley, M.J.N. and Park, R.: Seismic Design of Bridge Piers, Department of Civil Engineering, University of Canterbury, August, 1984.

24) Kunnath, S.K. and Reinhorn, A.M.: Efficient Modelling Scheme for Transient Analysis of Inelastic RC Structures, Microcomputer in Civil Engineering, Vol.10, No.1, pp.97-110, 1995.

(Received February 17, 2003) 